\title{
Correlation of ultrasonographic estimated fetal weight with actual birth weight at a rural setting
}

\author{
EInazeer A. Hashim1, Elsir A. Saeed ${ }^{2}$, Elsadig Y. Mohamed ${ }^{3 *}$, Elabbas M. Ebaid ${ }^{4}$, \\ Hussam Zain ${ }^{5}$, Sawsan M. Abdalla ${ }^{3}$, Khalid E. Medani ${ }^{3}$, Rayan G. Albarakati6
}

\begin{abstract}
${ }^{1}$ Department of Radiology, Faculty of Medicine, University of West Kordofan, Sudan
${ }^{2}$ Department of Radiology, Faculty of Graduate Studies, The National Ribat University, Sudan

${ }^{3}$ Department of Community Medicine and Public Health, College of Medicine, Majmaah University, Saudi Arabia

${ }^{4}$ Department of Radiology, College of Medicine, Majmaah University, Saudi Arabia

${ }^{5}$ Department of Obstetrics and Gynecology, College of Medicine, Majmaah University, Saudi Arabia/ College of Medicine, Alfashir University, Alfashir, Sudan

${ }^{6}$ Department of Obstetrics and Gynecology, College of Medicine, Majmaah University, Saudi Arabia
\end{abstract}

Received: 09 May 2020

Accepted: 08 June 2020

*Correspondence:

Dr. Elsadig Y. Mohamed,

E-mail: elsadigoo@gmail.com

Copyright: (C) the author(s), publisher and licensee Medip Academy. This is an open-access article distributed under the terms of the Creative Commons Attribution Non-Commercial License, which permits unrestricted non-commercial use, distribution, and reproduction in any medium, provided the original work is properly cited.

\section{ABSTRACT}

Background: Ultrasound estimation of fetal weight in term pregnancies is used to determine fetal growth. The objective of this study was to assess the precision of sonographic estimation of fetal weight in normal vaginal deliveries at a rural setting.

Methods: The study was cross-sectional. A group of 74 pregnant women delivered normally in Muglad hospital in West Kordofan, Sudan, were considered in the study. Fetal weight was estimated by Hadlock and shephards formulae within one week prior to delivery and then newborn weight was taken within 24 hours after delivery. Data were collected by a questionnaire and medical examination as well as sonographic examination. Data analysis was done by SPSS version 23 and Kruskal Wallis Test (post-hoc analysis) Pearson's correlation coefficient within 95\% confidence interval. p value $<0.05$ was considered as statistically significant.

Results: The correlation, by Paired sample, to assess fetal weight was as follows: between Hadlock and shephards was 0.901 ( $\mathrm{p}<0.001)$, between Hadlock and AFW was $0.908(\mathrm{p}<0.001)$ and between Shephards and AFW was $0.781(\mathrm{p}<0.001)$.

Conclusions: Estimation of fetal weight by Hadlock has been more correlated with actual fetal weight (AFW) than that done with shephards. The study recommends using Hadlock formula which is more accurate in estimation of fetal weight by sonography.

Keywords: Correlation, Fetal weight, Ultrasonographic estimation

\section{INTRODUCTION}

The ultrasound estimation of fetal weight in term pregnancies is used to determine growth, and this may affect the timing and route of delivery. ${ }^{1}$ Accurate prenatal estimation of fetal weight (EFW) in late pregnancy and labor is extremely useful in the management of labor and delivery, permitting obstetricians to make decisions about instrumental vaginal delivery, trial of labor after caesarean delivery and elective caesarean section for patients suspected of having fetal macrosomia. ${ }^{2}$

Correct EFW values are also important when intrauterine growth is restricted. ${ }^{3,4}$ 
The perinatal complications associated with low birth weight are most often attributable to fetal prematurity, but may sometimes also arise as the result of intrauterine growth retardation. For sizable fetuses, potential complications associated with delivery include shoulder dystocia, brachial plexus injuries, bone injuries, and intrapartum asphyxia, as well as maternal risks that include birth canal injuries, pelvic floor injuries and postpartum hemorrhage. During intrauterine period the fetus is measured by biometry, such as measuring fetal head, femur and abdomen. The results would be applied to specific charts which will tell whether the growth is normal or not. Moreover, the measurements can calculate the estimation of fetal weight (EFW), which is a good method to assess fetal growth during intrauterine period. ${ }^{5}$

Standardization for normal fetal growth and birth weight adjusted for constitutional variation are far better than local population norms to differentiate small fetuses that result from pathological or physiological factors. standard charts improve early recall of pathologically small babies.6,7 Small fetuses diagnosed by customized standards were associated with many pregnancy complications such as intrauterine fetal death and neonatal death, they are characterized by some pathological indicators such as doppler abnormalities and neonatal unit admission. ${ }^{8,9}$

Fetal weight is usually estimated by clinical assessment or by ultrasound, both have roughly equivalent accuracy, even in fetal macrosomia, so it is not advised to select one method over the other based on scientific ground. Nonetheless, estimation of fetal weight using ultrasound provides some measures of objectivity over clinical estimation. ${ }^{10}$

Regression models are frequently used for of fetal weight estimation, based on combinations of different biometric indices, such as femur length, abdominal circumference, head circumference and biparietal diameter. Some models use only one or two fetal indices; however, others add more fetal indices to improve accuracy.

Hadlock's formula, using femur length and AC, and Shephard's formula, using biparietal diameter and AC measurements, were the most used formulae to assess fetal weight. Ultrasound measurements tended to overestimate the weight of small babies while underestimating the weight of both large babies and the babies of diabetic mothers. ${ }^{11}$ fetal weight estimation in the third trimester of pregnancy is important factor in clinical decision making in obstetrics.

Abdominal palpation and measuring symphysis-fundus height are not accurate. Ultrasound estimation of fetal weight is considered more accurate for approximate estimation of fetal weight. It can serve to determine the weight of the fetus within $10 \%$ of actual birth weight (BW) in as many as $75 \%$ of estimates and within $5 \%$ in as many as $40 \%$. Errors in fetal weight estimation may be harmful if clinical decisions depend on such estimates result in premature delivery or lead to surgical intervention that may lead to unfavourable outcomes.

The objective of this study was to assess the precision of sonographic estimation of fetal weight in normal vaginal deliveries at a rural setting.

\section{METHODS}

Authors conducted a cross-sectional study using the baseline data from Al-Muglad hospital in West Kordofan State-Sudan. Seventy-four pregnant women between thirty-six- and forty-two-weeks of gestation within the last week before delivery selected from the maternity clinic and maternity word. Participants were excluded from the analyses if they were in their active stage of labor, had ruptured membranes, eclampsia, diabetics, previous cesarean section cases in which not all four biometric indices were recorded, twin pregnancy, congenital malformations and hydrops fetalis. Data obtained from the sample included personal history and clinical data which was taken from patients' files of perinatal follow up as well as from admission sheets.

Sonographic examination carried out for each participant after informed consent. Sonographic evaluation was done in a comfortable supine position. Data collected from sonographic examination included the standard fetal biometric measurements: abdominal circumference (AC), femoral length (FL), biparietal diameter (BPD), and head circumference (HC). the relevant head image required for the measurement of the biparietal diameter (BPD), occipital-frontal diameter (OFD) and head circumference (HC) is a transverse axial plane, which includes the falx cerebri anteriorly and posteriorly, cavum septum pellucidum anteriorly in the midline, and the thalami. The BPD should measure at the widest point of the head from the outer edge of the nearest parietal bone to the inner edge of the more distant parietal bone and the OFD perpendicular to the BPD from mid to mid occipital bones.

The head circumference traced either with an ellipse mode or manually around the outer perimeter of the skull. In late pregnancy it can be difficult to obtain the ideal imaging plane due to the head lying low in the pelvis.

The imaging plane for the abdominal circumference (AC) is a true transverse cut at the level of the fetal liver and stomach, including the left portal vein at the umbilical region. Although the $\mathrm{AC}$ can be measured using the ellipse mode, in the third trimester it is usually more precise to manually trace the perimeter of the abdomen, including the fat layer.

Long bones imaged in the axial plane to achieve the longest length, with clean blunt ends and a strong acoustic shadow behind the bone. Measuring must be along the diaphyseal shaft, excluding the epiphysis. 


\section{Antenatal data included}

Patient age (years), parity, gravidity, significant medical diseases gestational diabetes mellitus (GDM), fibroid, abnormal liquor volume, mode of delivery (vaginal delivery, vacuum extraction, caesarean delivery), time of scan to delivery (days), gestational age at delivery, and actual birth weights (BWs) of each participant's neonate was measured within $30 \mathrm{~min}$ after delivery, by trained midwives using a standardized neonatal weighing scale.

The fetal weight estimation compared with the actual $\mathrm{BW}$, and the following measures of accuracy were calculated for each model: (1) correlate with the actual birth weight (2) systematic error which reflects the systematic deviation of a model from the actual birth weight, expressed as the percentage of the actual birth weight; (3) random error, a measure of precision (rather than accuracy) that reflects the random (or nonsystematic) component of the prediction error.

\section{Statistical analysis}

Data analysis was performed with the SPSS version 23. To determine the personal data, frequencies, percentages and means (where appropriate) were computed. Percentages, means and standard deviations were first computed. ANOVA table were used to compare between more than or equal three groups. Independent sample ttest was used to compare between two groups in the mean. Kruskal Wallis test was used for three or more groups in the mean, this test considered non-parametric test. Pearson's correlation coefficient within 95\% confidence interval $\mathrm{p}$ values $<0.05$ were considered as statistically significant.

\section{RESULTS}

Table 1 shows characteristics of the women enrolled in the study.

Table 1: Characteristics of women $(n=74)$.

\begin{tabular}{|lll|}
\hline $\begin{array}{l}\text { Characteristics } \\
\text { Age }\end{array}$ & Frequency & Percentage \\
\hline 15-19 years & 10 & $13.5 \%$ \\
\hline 20-29 years & 34 & $45.9 \%$ \\
\hline 30-39 years & 28 & $37.8 \%$ \\
\hline 40 years and more & 2 & $2.7 \%$ \\
\hline Gravidity & \\
\hline Primigravida & 5 & $6.8 \%$ \\
\hline Multigravida & 42 & $56.8 \%$ \\
\hline Grand multigravida & 27 & $36.4 \%$ \\
\hline Gestational age at birth/weeks & \\
\hline $36-37$ & 1 & $1.4 \%$ \\
\hline $37-38$ & 16 & $21.6 \%$ \\
\hline $38-39$ & 45 & $60.8 \%$ \\
\hline $39-40$ & 8 & $10.8 \%$ \\
\hline More than 40 & 4 & $5.4 \%$ \\
\hline
\end{tabular}

Ten $(13.5 \%)$ of women were in the age group 15-19 years.

Thirty-four $(45.9 \%)$ in the age group 20-29 years, 28 $(37.8 \%)$ in the age group $30-39$ years, and $2(2.7 \%)$ were 40 years of age and more. Five women (6.8\%) were primigravidae, $42(56.8 \%)$ were multigravida while 27 $(36.4 \%)$ were grand multigravida. One woman $(1.4 \%)$ had gestational age between 36 and 37 weeks, $16(21.6 \%)$ were in the gestational age 37-38 weeks, $45(60.8 \%)$ had gestation age of $38-39$ weeks, $8(10.8 \%)$ were in the gestational age of $39-40$ weeks and $4(5.4 \%)$ had gestational age equal or more than 40 weeks.

Table 2: Multiple comparisons of estimated fetal weight (post-hoc analysis).

\begin{tabular}{|llll|}
\hline \multirow{2}{*}{ Factor } & Factor & $\begin{array}{l}\text { Mean } \\
\text { difference }\end{array}$ & $\begin{array}{l}\text { p- } \\
\text { value }\end{array}$ \\
\hline Hadlock & Shephard's & -34.878 & 0.507 \\
\cline { 2 - 4 } & AFW (in grams) & -44.527 & 0.397 \\
\hline Shephard's & Hadlock & 34.878 & 0.507 \\
\cline { 2 - 4 } & AFW (in grams) & -9.649 & 0.854 \\
\hline Actual fetal & Hadlock & 44.527 & 0.397 \\
\cline { 2 - 4 } weight/grams & $\begin{array}{l}\text { EFW by } \\
\text { shepherd's }\end{array}$ & 9.649 & 0.854 \\
\hline
\end{tabular}

Table 2 shows that there is higher difference in average EFW by Hadlock methods (44.527 grams) and actual fetal weight through post hoc analysis that is; Hadlock method on an average predicted 44.527 grams more than that of actual fetal weight $(\mathrm{p}=0.397)$.

The difference in prediction between shepherd's and actual fetal weight on average was 9.649 grams that is shepherd's methods on average predicted 9.649 grams higher weight than actual fetal weight $(\mathrm{p}=0.854)$.

Table 3: Comparison of estimated fetal weigh with different methods and actual fetal weight (independent sample t-test).

\begin{tabular}{|llll|}
\hline Fetal weight & $\mathbf{t}$ & df & p-value \\
\hline $\begin{array}{l}\text { EFW by Hadlock - EFW } \\
\text { by shepherd's }\end{array}$ & -0.658 & 146 & 0.512 \\
\hline $\begin{array}{l}\text { EFW by Hadlock - actual } \\
\text { fetal weight (AFW) }\end{array}$ & -0.868 & 146 & 0.387 \\
\hline $\begin{array}{l}\text { EFW by shepherd's - } \\
\text { actual fetal weight (AFW) }\end{array}$ & -0.182 & 146 & 0.856 \\
\hline $\begin{array}{l}\text { Gestational age: } \\
\text { estimated and at birth }\end{array}$ & -4.135 & 146 & $<0.001$ \\
\hline
\end{tabular}

Table 4: Paired sample correlation: estimated fetal weight.

\begin{tabular}{|lll|}
\hline Estimated fetal weight & Correlation & p-value \\
\hline Hadlock with shepherd's & 0.901 & $<0.001$ \\
\hline Hadlock with AFW & 0.908 & $<0.001$ \\
\hline Shephard's with AFW & 0.781 & $<0.001$ \\
\hline
\end{tabular}


Table 3 shows that, there is no significant different between means for EFW by Hadlock and shepherd's $(\mathrm{p}=0.512)$.

There is no significant difference between means for EFW by Hadlock and actual fetal weight ( $\mathrm{p}=0.387$ ), and there is no significant difference between means for EFW by shephards and actual fetal weight $(\mathrm{P}=0.856)$.

There is significant difference between gestational age as estimated and gestational age at birth ( $\mathrm{p}$-value $<0.001)$.

The correlation is significant for fetal weight estimation by Hadlock with shepherd's $(<0.001)$, Hadlock with AFW $(\mathrm{p}<0.001)$ and Shepherds with AFW $(\mathrm{p}<0.001)$. The correlation between estimated fetal weight by Hadlock and actual fetal weight is greater than the correlation between estimated fetal weight by shepherd's and actual fetal weight.

\section{DISCUSSION}

This study was conducted to compare the accuracy of sonographic models for fetal weight estimation (Hadlock's and Shepard's formulas) and to compare all with the actual fetal weight after delivery. By using Multiple comparisons of estimated fetal weight (post-hoc analysis), the mean difference between Hadlock's method and actual fetal weight in estimating fetal weight is $(44.527 \mathrm{~g})$, the difference is not statistically significant $(p=0.397)$. The mean difference between Shephard's method and the actual fetal weight is $(9.649 \mathrm{~g})$, the difference is not statistically significant $(\mathrm{p}=0.854)$. The mean difference of fetal weight estimation between Hadlock's method and Shephard's method is (34.878 g), the difference is not statistically significant $(\mathrm{p}=0.507)$. Results showed that the difference of fetal weight estimated by shepherd's method is closer to the actual compared with Hadlock method. These findings are consistent with the results of studies done previously by Ratanasiri T et al, Eze CU et al, Joshi A et al, Yadav R and Lima AMH et al. ${ }^{12-16}$

By using paired sample correlation for Estimated fetal weight, the correlation between estimated fetal weight by Hadlock and actual fetal weight is greater than the correlation between estimated fetal weight by shepherd's and actual fetal weight, this signifies that the estimated fetal weight by Hadlock is better than estimated fetal weight by shepherd's. From standard deviation, the estimation by Hadlock is centralized to the mean more than that estimated by Shephard's. These results are in line with the studies conducted elsewhere which found the Hadlock formulas to be the most accurate in estimation fetal weight. ${ }^{17,18,19-24}$

\section{CONCLUSION}

The study concluded that: estimation of fetal weight by Hadlock has been more correlated with actual fetal weight (AFW) than that done with shepherd's. The study recommends using Hadlock formula which is more accurate in estimation of fetal.

\section{ACKNOWLEDGMENTS}

The authors would like to acknowledge the administration of Al-Muglad hospital. for their support in this research work. Authors thanks extend to the women who participated in this research.

\section{Funding: No funding sources}

Conflict of interest: None declared

Ethical approval: The study was approved by the Institutional Ethics Committee

\section{REFERENCES}

1. Royal College of Obstetricians and Gynecologists. The investigation and management of the small-forgestational age fetus. No. $31,2^{\text {nd }}$ edn London: Royal College of Obstetricians and Gynaecologists, 2013.

2. Ashrafganjooei T, Naderi T. Eshrati B, Babapoor N. Accuracy of ultrasound, clinical and maternal estimates of birth weight in term women. EMHJ. 2010;16(3):313-7.

3. Sharma D, Shastri S, Sharma P. Intrauterine growth restriction: antenatal and postnatal aspects. Clin Med Insights Pediatr. 2016;10:67-83.

4. Albu AR, Horhoianu IA, Dumitrascu MC, Horhoianu V. Growth assessment in diagnosis of fetal growth restriction. Review J Med Life. 2014;7(2):150-4.

5. Gardosi J. Ultrasound biometry and fetal growth restriction. Fetal Matern Med Rev. 2002;13(4):24959.

6. Gardosi J, Francis A, Turner S, Williams M. Customized growth charts: rationale, validation and clinical benefits. Expert Review. 2018;218(2):S609S618.

7. Zhang J, Merialdi M, Platt LD, Kramer MS. Defining normal and abnormal fetal growth promises and challenges. Am J Obstet Gynecol. 2010;202(6):522-8.

8. Sharma D, Shastri S, Sharma P. Intrauterine growth restriction: antenatal and postnatal aspects. Clin Med Insights Pediatr. 2016;10:67-83.

9. Bertino E, Oggè G, Di Nicola P, Giuliani F, Coscia A, Todros T. Intrauterine Growth Restriction: Obstetric and Neonatal Aspects. Intervention Strategies. In: Buonocore G, Bracci R, Weindling M. (eds) Neonatol; 2016:1-23.

10. Lanowski JS, Lanowski G, Schippert C, Drinkut K, Hillemanns P, Staboulidou I. Ultrasound versus clinical examination to estimate fetal weight at term. Geburtshilfe Frauenheilkd. 2017;77(3):276-83.

11. Colman A, Maharaj D, Hutton J, Tuohy J. Reliability of ultrasound estimation of fetal weight in term singleton pregnancies. N Z Med J. 2006;119(1241):U2146. 
12. Ratanasiri T, Jirapornkul S, Somboonporn W, Seejorn K, Patumnakul P. Comparison of the accuracy of ultrasonic fetal weight estimation by using the various equations. J Med Assoc Thai. 2002;85(9):962-7.

13. Eze CU, Egwuanumku KI, Agwuna KK, Odidi L, Ochie K, Nwadike IU. Validity of common ultrasound methods of fetal weight estimation in late pregnancy among women in Kwale, Niger Delta region, Nigeria. Afr Health Sci. 2015;15(1):206-16.

14. Joshi A, Panta O, Sharma B. Estimated fetal weight: comparison of clinical versus ultrasound estimate. J Nepal Health Res Council. 2017;15(1):51-5.

15. Yadav R, Sharma B, Deokota R, Rahman H. Assessment of clinical methods and ultrasound in predicting fetal birth weight in term pregnant women. Int J Reprod Contracept Obstet Gynecol. 2016;5(8):2775-9.

16. Lima AMH, Carvalho PRN, Junior SCG, Carioca ACCM, Lopez JM. Analysis of the performance of 11 formulae for fetal weight estimation in preterm fetuses with abnormal doppler velocimetry - a retrospective multicenter study. Rev Bras Ginecol Obstet. 2018;401(10):580-6.

17. Melamed N, Yogev Y, Meizner I, Mashiach R, Bardin R, Ben-Haroush A. Sonographic fetal weight estimation: which model should be used? J Ultrasound Med. 2009;28:617-29.

18. Heer IM, Kumper C, Vogtle N, Muller-Egloff S, Dugas M, Strauss A. Analysis of factors influencing the ultrasonic fetal weight estimation. Fetal Diagn Ther. 2008;23:204-10.

19. Eze CU, Abonyi LC, Njoku J, Okorie U, Owonifari O. Correlation of ultrasonographic estimated fetal weight with actual birth weight in a tertiary hospital in Lagos, Nigeria. Afr Health Sci. 2015;15(4):11122.

20. Westerway SC. Estimating fetal weight for best clinical outcome. Aust J Ultra Med. 2012;15(1):13-7.

21. Mills MD, Nageotte MP, Elliott JP, Crade M, Dorchester W. Reliability of ultrasonographic formulary in the prediction of fetal weight and survival of very-low-birth-weight infants. Am J Obstet Gynecol. 1990;163:1568-74.

22. Siemer J, Wolf T, Hart N, Schrauder M, Meurer B, Goecker T, et al. Increased accuracy of fetal weight estimation with a gender-specific weight formula. Fetal Diagn Ther. 2008;24:321-6.

23. Siemer J, Egger N, Hart N, Meurer B, Müller A, Dathe O, Goecke T, Schild RL. Fetal weight estimation by ultrasound: comparison of 11 different formulae and examiners with differing skill levels. Ultraschall in der Medizin-European $\mathbf{J}$ Ultrasound. 2008;29(02):159-64.

24. Milner J, Arezina J. The accuracy of ultrasound estimation of fetal weight in comparison to birth weight: a systematic review. Ultrasound. 2018;26(1):32-41.

Cite this article as: Hashim EA, Saeed EA, Mohamed EY, Ebaid EM, Zain H, Abdalla SM, et al. Correlation of ultrasonographic estimated fetal weight with actual birth weight at a rural setting. Int J Reprod Contracept Obstet Gynecol 2020;9:2973-7. 